\title{
Faktor yang Mempengaruhi Keputusan Petambak dalam Memilih Pola Budidaya Udang Vannamei di Kecamatan Peudada Kabupaten Bireuen
}

\section{The Factors Affecting the Farmers Decision in Determining The Cultivation Pattern of WhiteShrimp (Litopenaeusvannamei) in Peudada Subdistrict, Bireuen}

\author{
Zuriani $^{1}$, Martina ${ }^{2}$, dan Cut Rizki Nanda Putri ${ }^{3}$ \\ ${ }^{1}$ Program StudiAgribisnis Fakultas Pertanian, Universitas Malikussaleh, Zuriani@unimal.ac.id \\ ${ }^{2}$ Program Studi Agribisnis Fakultas Pertanian, Universitas Malikussaleh \\ ${ }^{3}$ Program Studi Agribisnis Fakultas Pertanian, Universitas Malikussaleh
}

\begin{abstract}
Abstrak
Kecamatan Peudada merupakan salah satu kawasan penghasil udang vannamei di Kabupaten Bireuen dengan jumlah produksi sebesar 450,46 ton. Proses budidaya udang vannamei menggunakan dua pola yaitu intensif dan pola tradisional. Pola Intensif tergantung memerlukan modal yang lebih banyak untuk membeli peralatan dan pakan dibandingkan pola tradisional. Namun demikian, di lokasi penelitian banyak dijumpai petani yang memiliki banyak modal namun menggunakan pola tradisional dalam proses budidaya. Tujuan penelitian ini adalah untuk mengetahui faktor-faktor yang mempengaruhi keputusan petani dalam memilih pola budidaya udang vannamei di Kecamatan Peudada. Penelitian dilaksanakan pada bulan Agustus 2017 dengan sampel sebanyak 60 orang petambak yang terdiri dari 26 petambak pola intensif dan 34 pola tradisional. Untuk menganalisis data menggunakan model analisis Logistik (logit). Hasil penelitian menunjukkan bahwa yang mempengaruhi petambak dalam memilih pola budidaya di Kecamatan Peudada Kabupaten Bireuen adalah jarak lokasi dengan arus listrik, sedangkan modal tidak mempengaruhi petambak dalam memilih pola budidaya udang vannamei.
\end{abstract}

Katakunci: keputusan petambak, budidaya, udang vannamei

\begin{abstract}
Peudada Subdistrict is one of the vannamei shrimp producing areas in Bireuen Regency with a total production of 450.46 tons. The vannamei shrimp cultivation process uses two patterns, namely intensive and traditional patterns. Intensive patterns depend on more capital to buy equipment and feed than traditional patterns. However, many research sites found farmers who had a lot of capital but used traditional patterns in the cultivation process. The purpose of this study was to determine the factors that influence farmers' decisions in choosing the pattern of vannamei shrimp cultivation in Peudada District. The study was conducted in August 2017 with a sample of 60 farmers consisting of 26 intensive pattern farmers and 34 traditional patterns. To analyze data using the Logistics analysis model (logit). The results showed that influencing farmers in choosing the cultivation pattern in Peudada Subdistrict, Bireuen District was the distance between the location and the electric current, while the capital did not affect the farmers in choosing the vannamei shrimp cultivation pattern.
\end{abstract}

Keywords: decision of farmers, cultivation, vannamei shrimp 


\section{Pendahuluan}

Salah satu usaha di bidang perikanan yang mampu meningkatkan kesejahteraan petani yaitu budidaya udang vannamei. Vannamei (Litopenaeusvannamei)merupakan udang asli perairan Amerika Latin. Udang ini dibudidayakan mulai dari Pantai Barat Meksiko ke arah selatan hingga daerah Peru. Budidaya udang ini mulai berkembang dengan cepat di kawasan Asia, seperti Taiwan, Cina, dan Malaysia, bahkan kini di Indonesia. Pada tahun 1999, beberapa petambak di Indonesia mulai membudidayakan udang vannamei. Kehadiran udang vannamei menjadi penyelamat dunia pertambakan di Indonesia. Pertambakan mulai bergairah kembali, begitu juga dengan para pembenih udang, mereka mulai membenihkan udang vannamei untuk memenuhi kebutuhan petambak. Awal mula pembudidaya udang vannamei dilakukan di Jawa Timur. Petambak di Jawa Timur sangat antusias terhadap Udang vannamei, bahkan $90 \%$ petambak mengganti komoditas budidayanya dari udang windu menjadi udang vannamei[1]

Kecamatan Peudada merupakan salah satu kawasan penghasil udang vannamei di Kabupaten Bireuen dengan jumlah produksi mencapai 450,46 ton dari total jumlah produksi di Kabupaten Bireuen sebanyak 969,20 ton. Sebelumnya petani tambak di Kecamatan Peudada membudidayakan udang windu, namun produksi udang windu mengalami penurunan karena penyakit bercak putih. Oleh karena itu, sejak tahun 2010, petani dengan didampingi oleh penyuluh mulai beralih membudidayakan udang vannamei[2]. Udang vannamei memiliki sejumlah keunggulan antara lain lebih tahan penyakit, pertumbuhan lebih cepat, tahan terhadap gangguan lingkungan, waktu pemeliharaan yang lebih pendek yaitu sekitar 100-120 hari, kelangsungan hidup tinggi dan udang vannamei juga dapat ditebar dengan kepadatan 50-200 ekor $/ \mathrm{m}^{2}[3]$. Budidaya udang vannamei oleh masyarakat Peudada menggunakan dua pola yaitu pola intensif dan pola tradisional. Pola intensif merupakan pola budidaya yang menggunakan kincir dan membutuhkan modal awal yang besar dibandingkan dengan pola tradisional. Namun dilapangan diketahui bahwa terdapat beberapa petani yang memiliki modal besar namun melakukan budidaya dengan pola tradisional. Berdasarkan kondisi tersebut, maka perlu dilakukan penelitian untuk mengetahui faktor-faktor yang mempengaruhi keputusan petani dalam memilih pola budidaya udang vannamei di Kecamatan Peudada.

\section{Metode Penelitian}

Metode yang digunakan dalam penelitian ini adalah metode survey, yaitu melakukan wawancara dan pengamatan langsung di lapangan guna mendapatkan gambaran yang jelas tentang keputusan petambak dalam memilih pola budidaya udang vannamei di Kecamatan Peudada Kabupaten Bireuen. Penelitian dilakukan pada bulan Agustus 2017. Penelitian ini dilaksanakan di Kecamatan Peudada, yaitu Gampong Meunasah Blang, Gampong Baro, dan Gampong Paya. Jumlah populasi dalam penelitian ini adalah 112 orang petambak yang terdiri dari 48 petambak intensif (48\%) dan 64 petambak tradisional (57\%). Pengambilan data dilakukan secara acak sederhana (simple random sampling). Jumlah sampel yang diambil adalah 60 orang petambak yang terdiri dari 26 petambak pola intensif dan 34 pola tradisional.

Penelitian menggunakan data primer dan data sekunder. Data primer diperoleh dari hasil wawacara yang dilakukan dengan menggunakan kuisioner pada petambak udang vannamei yang menjadi sampel yaitu Meunasah Blang, Gampong Baro, dan Gampong Paya Kecamatan Peudada Kabupaten Bireuen. Data sekunder diperoleh dari studi pustaka dan instansi pemerintah terkait seperti Dinas Kelautan dan Perikanan Kabupaten Bireuen, Biro Pusat Statistik, Kantor Kecamatan Peudada Kabupaten Bireuen.

Data yang didapatkan digunakan untuk menganalisis faktor-faktor yang mempengaruhi keputusan petambak dalam memilih pola budidaya udang vannamei di Kecamatan Peudada Kabupaten Bireuen. Variabel yang digunakan dalam penelitian ini adalah modal dan lokasi. Modal digunakan untuk mengukur pengeluaran yang dibutuhkan sedangkan lokasi digunakan untuk melihat ketersediaan arus listrik dalam mengukur jarak dengan sumber arus listrik. Kedua variable tersebut dipilih berdasarkan observasi dilapangan yang menunjukkan bahwa pembudidaya udang vannamei pola intensif memerlukan modal yang besar dan tergantung pada arus listrik. Untuk menganalisis data menggunakan model analisis Logistik (logit). 
Fungsi tersebut dirumuskan sebagai berikut:

$$
\mathrm{Y}=\beta_{0}+\beta_{1} \mathrm{X}_{1}+\beta_{2} \mathrm{X}_{2}+\mathrm{e}
$$

\section{Keterangan :}

$$
\begin{aligned}
\mathrm{Y} & =\text { pola intensif atau pola tradisional } \\
\beta_{0^{-}} \beta_{3} & =\text { intersep } \\
\mathrm{X}_{1} & =\text { Modal }(\mathrm{Rp}) \\
\mathrm{X}_{2} & =\text { Lokasi }(\mathrm{M}) \\
\mathrm{e} & =\text { Error term }
\end{aligned}
$$

Analisis Regresi logistik biner (binomial) digunakan untuk melihat pengaruh variabel bebas $(\mathrm{X} 1, \mathrm{X} 2)$ terhadap variabel $(\mathrm{Y})$ yang berupa variabel terikat biner yang hanya mempunyai dua nilai. Model logit adalah suatu cara untuk mengkuantitatifkan hubungan dua pilihan (pola intensif atau pola tradisional), yaitu kategori pola intensif ( $\mathrm{Y}=1)$ dan pola tradisional $(\mathrm{Y}=0)$. Data dianalisis menggunakan alat analisis SPSS 21.

\section{Kriteria Pengujian Untuk Regresi Logistik[4]}

1. Uji Kelayakan Model Regresi

a. $\quad$ Koefisien Determinasi (Nagelkerke $R$ Square)

Nagelkerke $R$ Square adalah pengujian yang dilakukan untuk mengetahui berapa besar variabel independen mampu menjelaskan dan mempengaruhi variabel dependen. Nilai Nagelkerke R Square bervariasi antara 1 (satu) sampai 0 (nol), jika nilai semakin mendekati 1 maka model dianggap semakin goodnesof fit, sementara jika semakin mendekati 0 maka model dianggap tidak goodnessof fit.

b. Uji HosmerandLemeshow's Goodnesof fit test

Kelayakan model regresi dinilai dengan menggunakan HosmerandLomeshow'sGoodneesof fit test. Dengan kriteria sebagai berikut:

- Jika nilai HosmerandLemeshow'sGoodneesof Fit Test sama dengan atau kurang dari 0,05 maka berarti ada perbedaan signifikan antara model dengan nilai observasinya sehingga model tidak dapat memprediksi nilai observasinya.

- Jika nilai HosmerandLemeshow'sof Fit Test lebih besar dari 0,05 maka berarti model mampu memprediksi nilai observasinya atau dapat dikatakan model dapat diterima karena cocok dengan observasinya.

c. Uji Multikolinearitas

Uji Multikolinearitas bertujuan untuk menguji apakah dalam model regresi ditemukan adanya korelasi antar variabel bebas. Multikolinieritas terjadi jika koefisien korelasi (r)> 0,8. Koefisien korelasi menujukkan keeratan hubungan antar variabel dengan kriteria sebagai berikut :

Tabel 1. Tabel kriteria koefisien korelasi

\begin{tabular}{cc}
\hline Nilai & Interpretasi \\
\hline 0 & Tidak berkorelasi \\
$0,00-0,25$ & Korelasi sangat lemah \\
$0,25-0,50$ & Korelasi cukup \\
$0,50-0,75$ & Korelasi kuat \\
$0,75-0,99$ & Korelasi sangat kuat \\
1 & Korelasi sempurna \\
\hline
\end{tabular}

2. Uji Hipotesis

a. Uji G

UjiG atau pengujian secara keseluruhan/Uji signifikan model (Overall Test). Uji signifikan untuk mengetahui pengaruh variabel bebas terhadap variabel tidak bebas (terikat) didalam model, maka diuji dengan uji Likelihood.

- Jika nilai signifikan dari $\mathrm{G} \leq 0,05$ maka variabel independen secara simultan berpengaruh signifikan terhadap variabel dependen. 
- Nilai nilai signifikan >0,05 maka variabel independen secara simultan tidak berpengaruh signifikan terhadap variabel dependen.

b. Uji Parsial/ Uji Parameter Model (Uji Wald)

Pada umumnya, uji ini dilakukan setelah uji signifikan model memutuskan bahwa minimal ada satu variabel bebas yang memiliki pengaruh signifikan terhadap variabel terikat. Tujuannya adalah untuk mencari tahu manakah variabel bebas yang berpengaruh signifikan terhadap variabel terikat tersebut.

Pengujian keberartian parameter ( koefisien $\beta$ ) secara parsial dapat dilakukan melalui uji wald dengan kriteria sebagai berikut:

- Jika nilai signifikan dari $\mathrm{W} \leq 0,05$ maka variabel independen secara parsial berpengaruh signifikan terhadap variabel dependen.

- Jika nilai signifikan dari $\mathrm{W}>0,05$ maka variabel independen secara parsial tidak berpengaruh signifikan terhadap variabel dependen.

\section{Hasil dan Pembahasan}

Budidaya Udang Vannamei

Pembahasan budidaya udang vannamei yang dilakukan adalah budidaya udang vannamei dengan menggunakan pola tradisional dan menggunakan pola intensif.

\section{Budidaya Udang Vannamei dengan Menggunakan Pola Tradisional}

a. Membersihkan Tambak

Sebelum tambak digunakan terlebih dahulu air yang ada di dalam tambak dibersihkan dengan menggunakan samponi dan didiamkan selama 3 hari, manfaatnya untuk menyingkirkan ikan dan hama-hama lainnya, karena ikan termasuk salah satu hama pemangsa benur.

b. Pemupukan

Setelah 3 hari di lakukan pemupukan dengan menggunakan pupuk MPK Bas $5 \mathrm{~kg} / \mathrm{ha}$ dan sebaliknya dalam persiapan tambak digunakan juga pupuk organik (pupuk kandang) antara 2000-2500 kg/ha.Pemupukan berfungsi untuk mengembalikan kesuburan tanah, sehingga pakan alami dapat tumbuh dengan baik.

c. Penebaran Benur

Setelah 22 hari, benur sudah bisa untuk ditebar, dan sebelum ditebar sebaiknya dilakukan penyesuaian terlebih dahulu yang bertujuan agar benur dapat beradaptasi dengan keadaan baru dan tidak mengakibatkan benur menjadi stres. Penyesuaian tersebut dilakukan dengan cara mengapungkan kantong plastik yang berisikan benur kedalam tambak. Proses ini dilakukan kurang lebih selama 2 jam, waktu penebaran yang ideal dilakukan pagi dan sore hari ketika suhu air rendah, kepadatan udang vannamei rata-rata yaitu 54.688/ha.

d. Pakan

Pakan mulai diberikan ketika umur benur mencapai 15 hari, hal ini dilakukan karena pada saat umur benur masih di bawah 15 hari, benur masih bisa mengkonsumsi pakan alami berupa plankton dalam tambak dan ketersedian plankton akan mempertahankan kondisi kimiawi air yang mendukung kehidupan dan pertumbuhan udang. Pemberian pakan harus dilakukan dengan tepat untuk menjamin udang mengkonsumsi pakan secara maksimal dan tidak meninggalkan kelebihan pakan pada tambak .

e. Pemeliharaan

Setelah itu bagian pemeliharaan, pemeliharaan dilakukan dengan memperhatikan perubahan benur dari hari kehari sehingga sampai saat panen, sepanjang pemeliharaan harus tetap memperhatikan suhu dan $\mathrm{ph}$ air, dan pada tahap pemeliharaan ini dapat dilakukan pemupukan urea dan omyam untuk menstabilkan perkembangan plankton dan air tambak, pemberian pakan hingga umur 100-120 hari. Udang siap untuk dipanen, pemanenan dilakukan pada malam hari untuk menghindari terik mata hari dan mengurangi resiko udang ganti kulit selama panen akibat stress.

\section{Budidaya Udang Vannamei dengan Menggunakan Pola intensif}

a. Pengapuran

Sebelum tambak dialiri air terlebih dahulu dilakukan pengapuran,yang bertujuan untuk menaikkanph tanah dan mempertahankannya dalam kondisi yang stabil. Selain itu tanah 
diharapkan dapat menjadi lebih subur, kapur yang digunakan dalam pengapuran adalah kapur dolomite yang mengandung unsur magnesium dengan dosis $20 \mathrm{sak} / \mathrm{ha}$.

b. Pemberantas Hama dan Penyakit

Setelah 4 hari pengapuran, dilakukan pemberantasan hama dan penyakit dengan pemberian klorin dan samponi. Klorin berfungsi sebagai pemberantas fitoplankton sehingga air mudah dicerahkan. Sedangkan samponi berfungsi sebagai bahan racun untuk membunuh ikan atau hama lainnya yang mengganggu pertumbuhan udang vannamei.

c. Pemupukan

Setelah 3 hari, dilakukan pemupukan dengan menggunakan pupuk alami maupun pupuk buatan seperti pupuk Sp36, urea, dan MPK5 kg/ha dan sebaiknya dalam persiapan tambak digunakan juga pupuk organik (pupuk kandang) antara 2000-2500 kg/ha. Pemupukan berfungsi untuk mengembalikan kesuburan tanah, sehingga pakan alami dapat tumbuh dengan baik.

d. Pemasangan Kincir

Pemasangan kincir dilakukan pada hari ke 20 setelah pemupukan, yang berfungsi sebagai penyuplai oksigen dalam tambak, sehingga dapat membantu mengarahkan kotoran dasar tambak kearah sentral pembuangan, sehingga mempermudah dalam proses pembersihan dasar tambak. Untuk luas tambak 1 ha diperlukan kurang lebih 6 buah kincir.

e. Penebaran Benur

Setelah 3 hari pemasangan kincir, Benur siap ditebar dan sebaiknya benur yang akan ditebar berumur 7-10 hari, sebelum ditebar dilakukan penyesuaian terlebih dahulu yang bertujuan agar benur dapat beradaptasi dengan keadaan baru dan tidak mengakibatkan benur menjadi strees. Penyesuaian tersebut dilakukan dengan cara mengapungkan kantong plastik yang berisikan benur kedalam tambak. Proses ini dilakukan kurang lebih selama 2 jam, waktu penebaran yang ideal dilakukan pagi dan sore hari ketika suhu air rendah,kepadatan udang vannamei rata-rata yaitu 208.813/ha.

f. Pakan

Pakan mulai diberikan pada saat benur ditebar ketambak, pakan yang digunakan juga harus yang berkualitas baik dan tidak mengandung penyakit. Pemberian pakan harus dilakukan dengan tepat untuk menjamin udang mengkonsumsi pakan secara maksimal dan tidak meninggalkan kelebihan pakan pada tambak.

g. Perawatan dan panen

Perawatan dilakukan denganmemperhatikan perubahan benur dari hari kehari sehingga sampai saat panen, sepanjang pemeliharaanharus tetap memperhatikan suhu dan ph air, dan pada tahap pemeliharaan ini dapat dilakukan pemupukan super MB, Super PS, dan omyam untuk menstabilkan perkembangan dan air tambak. Udang vannamei dapat dipanen setelah berumur 100-120 hari, pemanenan dilakukan pada malam hari untuk menghindari terik mata hari dan mengurangi resiko udang ganti kulit selama panen akibat stress.

\section{Analisis Faktor-Faktor yang Mempengaruhi Keputusan Petambak dalam Memilih Pola Budidaya Udang Vannamei}

Analisis faktor-faktor yang mempengaruhi keputusan petambak dalam memilih pola budidaya udang vannamei di Kecamatan Peudada Kabupaten Bireuen dilakukan menggunakan model regresi binary logistik. Dalam hal ini maka pola budidaya tradisional diberikan nilai 0 dan pola budidaya udang intensif diberikan nilai 1 . Jumlah data yang digunakan dalam penelitian ini sebanyak 60.

\section{Uji Kelayakan Model Regresi}

1. Koefisien Determinasi (Nagelkerke R Square)

Untuk mengetahui seberapa besar variabel independen mampu menjaleskan dan mempengaruhi variabel dependen juga diestimasi dengan Cox andSnell'sandNagelkerke's $\mathrm{R}^{2}$.Nagelkerke's adalah modifikasi lanjutan bagi koefisien Cox dan Snell's untuk memastikan bahwa nilainya 0 dan 1. Biasanya nilai Negelkerke R Square dapat dilihat pada Tabel 2. 
Tabel 2. Uji Nagelkerke R Square

\begin{tabular}{cccc}
\hline Step & -2 Log likelihood & Cox \&Snell R Square & Nagelkerke R Square \\
\hline 1 & $46.591^{\mathrm{a}}$ & .447 & .599 \\
\hline
\end{tabular}

Dari Tabel 2, dapat dilihat bahwa Nagelkerke R Square 0,599. Nilai tersebut menunjukkan kekuatan model yang digunakan dalam penelitian. Dari nilai tersebut dapat diartikan bahwa variabel indenpenden mampu menjelaskan variabel dependen sebesar 59,9\%, sedangkan sisanya $40,1 \%$ dijelaskan diluar model.

2. Uji HosmerandLomeshow'sGoodneesofFit Test

Model estimasi statistik HosmerandLomeshowmenyediakan informasi kaliberasi model. Hasil analisis HosmerandLomeshow dapat dilihat pada tabel berikut :

Tabel 3. HomesandLomeshowTest

\begin{tabular}{cccc}
\hline Step & Chi-square & Df & Sig. \\
\hline 1 & 6.988 & 8 & 0.538 \\
\hline
\end{tabular}

Tahap signifikan observasi bagi nilai chisquare $\left(x^{2}\right)$ yang diperoleh adalah 6.988 (Uji Hosmer dan Lemeshow) dan nilai sig adalah $0,538>\alpha(0,05)$. Maka berarti model mampu memprediksi nilai observasinya atau dapat dikatakan model diterima karena cocok dengan data obsersinya dan bisa dijadikan sebagai sumber informasi.Oleh sebab itu dapat menunjukan penjelas data yang baik.

3. Uji multikolinieritas

Ada model regresi logistik, satu-satunya asumsi yang harus dipenuhi adalah distribusi normal pada error dan hasil estimasi. Syarat tersebut tidak memerlukan pengujian khusus dan hampir selalu terpenuhi pada semua jenis data. Meskipun begitu tetap perlu dilakukan pengujian multikolinieritas untuk mengetahui apakah ada korelasi yang kuat antara variabel indenpenden pada model ini.

Tabel 4. Uji multikolinieritas sebelum dilakukan perbaikan

\begin{tabular}{rlrrrr}
\hline \multicolumn{2}{c}{ Constant } & x1 & x2 & x3 \\
\hline Step 1 & Constant & 1.000 & -.528 & .403 & -.918 \\
& x1 & -.528 & 1.000 & -.931 & .643 \\
& x2 & .403 & -.931 & 1.000 & -.609 \\
& x3 & -.918 & .643 & -.609 & 1.000 \\
\hline
\end{tabular}

Dari tabel 4, dapat dilihat hasil analisis yang pertama menunjukkan bahwa terjadinya multikolenieritas karena adanya korelasi antar variabel bebas yang melebihi 0,8 , sehingga dapat disimpulkan terjadi masalah multikolinieritas.Ouputdari pengujian terakhir untuk Uji multikolinieritas dapat dilihat pada tabel berikut:

Tabel 5. Uji multikolinieritas setelah dilakukan perbaikan

\begin{tabular}{|c|c|c|c|c|}
\hline & & Constant & $\mathrm{x} 1$ & $\mathrm{x} 2$ \\
\hline \multirow{3}{*}{ Step 1} & Constant & 1.000 & .029 & -.664 \\
\hline & $\mathrm{x} 1$ & .029 & 1.000 & -.637 \\
\hline & $\mathrm{x} 2$ & -.664 & -.637 & 1.000 \\
\hline
\end{tabular}

Pada pengujian multikolinieritas, indikasi adanya korelasi yang kuat antar variabel independen ditunjukan dengan angka korelasi yang melebihi 0,6 . Hasil penelitian menunjukkan bahwa tidak ada angka korelasi antar variabel indenpenden yang melebihi 0,8 , sehingga dapat disimpulkan tidak terdapat masalah multikolinieritas pada variabel-variabel independen dalam model.

\section{Uji Hipotesis}

1. Ujib G (Chiquare) dilakukan untuk menguji tingkat signifikan suatu model dalam penelitian.Hasil analisis Uji G dapat dilihat pada Tabel 6 berikut: 
Tabel 6. Omnibus Testsof Model Coefficients

\begin{tabular}{llccc}
\hline & & Chi-square & Df & Sig. \\
\hline Step 1 & Step & 35.517 & 2 & .000 \\
& Block & 35.517 & 2 & .000 \\
& Model & 35.517 & 2 & .000 \\
\hline
\end{tabular}

Uji $\mathrm{G}$ bagi model koefisien untuk mengetahui pengaruh variabel bebas terhadap variabel tidak bebas, dimana semua hubungan dan koefisien ekpektasi dengan nol adalah $x^{2}=35.517$ derajat kebebasan adalah 2 dan nilai sig $=0,000$. Hal ini menunjukkan bahwa regresi logistik berpengaruh signifikan. Variabel dependen berkaitan dengan setiap variabel independen dan keseluruhan model sangat signifikan secara statisik,meskipun tidak mengambarkan keseluruhan bagi setiap variabel yang dikaji. Dapat disimpulkan bahwa varibel bebas yang digunakan dalam model secara bersamaan berpengaruh terhadap pemilihan pola budidaya oleh petambak udang vannamei.

2. Uji Parsial/ Uji Parameter Model (Uji Wald)

Dilakukan untuk mencari tahu manakah variabel bebas yang signifikan mempengaruhi variabel terikat. Hasil analisis uji wald/uji parsial dapat dilihat pada tabel berikut:

Tabel 7. Variables in theEquation

\begin{tabular}{llrrrrrr}
\hline & & \multicolumn{1}{c}{ B } & \multicolumn{1}{c}{ S.E. } & \multicolumn{1}{c}{ Wald } & df & \multicolumn{1}{c}{ Sig. } & \multicolumn{1}{c}{$\operatorname{Exp(B)}$} \\
\hline Step 1 $^{\mathrm{a}}$ & $\mathrm{x} 1$ & .000 & .000 & 9.548 & 1 & .002 & 1.000 \\
& $\mathrm{x} 2$ & -.003 & .001 & 11.067 & 1 & .001 & .997 \\
& Constant & .946 & .665 & 2.023 & 1 & .155 & 2.574 \\
\hline
\end{tabular}

Persamaan model sebagai berikut :

$$
\mathrm{Y}==0,946+0,000 \mathrm{X}_{1}-0,003 \mathrm{X}_{2}
$$

Dari tabel diatas dapat dilihat bahwa variabel modal $\left(\mathrm{X}_{1}\right)$ tidak berpengaruhkarena nilai koefesiennya sebesar 0.000 .Hasil penelitian menunjukan bahwa pola tradisional juga memerlukan modal yang besar untuk pembelian pakan, karena ditempat penelitian pola tradisional yang digunakan tidak sepenuhnya alami. Sebagian petambak ditempat penelitian memiliki modal yang cukup untuk melakukan budidaya secara intensif tetapi petambak tidak menggunakan pola intensif, alasan petambak karena tidak berani mengambil resiko.

Variabelyang mempengaruhi petambak dalam memilih pola budidaya udang vannamei adalah jarak lokasi dengan arus listrik $(0,001<0,05)$. Hasil analisis menunjukkan bahwa nilai koesfisien estimasi dari variabel jarak lokasi tambak dengan jarak arus listrik $\left(\mathrm{X}_{2}\right)$ berpengaruh negatif terhadap pemilihan pola budidaya. Hal ini menunjukan bahwa semakin jauh jarak lokasi tambak dengan arus listrik maka akan membuat petani lebih memilih pola budidaya tradisional, dan sebaliknya semakin dekat jarak lokasi tambak dengan arus listrik maka akan membuat petani lebih memilih pola intensif. Estimasi probabilitas menunjukan bahwa petambak yang melakukan budidayanya jauh dari arus listrik mempunyai peluang 0,997 kali untuk tidak memilih pola budidaya intensif dibandingkan dengan petambak yang melakukan budidayanya dekat dengan arus listrik. Perilaku seperti ini dianggap wajar karena jarak lokasi tambak dengan arus listrik akan berpengaruh terhadap pemilihan pola budidaya intensif, karena bila arus listrik dekat dengan lokasi maka petambak akan lebih mudah mengakses lampu dan hal ini juga mempermudah petambak dalam pemasangan kupu-kupu (kincir).

\section{Kesimpulan}

Berdasarkan hasil penelitian yang telah dilakukan dengan menggunakan analisis regresi logistik dapat disimpulkan bahwa yang mempengaruhi petambak dalam memilih pola budidaya di Kecamatan Peudada Kabupaten Bireuen adalah jarak lokasi dengan arus listrik, sedangkan modal tidak mempengaruhi petambak dalam memilih pola budidaya udang vannamei. 


\section{Daftar Pustaka}

[1] Haliman, Widodo, Rubiyanto,.Adijaya Dian S,. 2005. Udang Vannamei. Penebar Swadaya

[2] Dinas Kelautan dan Perikanan (DKP). 2015. Kabupaten Bireuen.

[3] Amri,dkk. 2008. Budidaya Udang Vaname Secara Intensif, Semi Intensif ,dan Tradisional. Jakarta, Gramedia Pustaka Utami.

[4] Ghozali, 1. 2011. Aplikasi Analisis multivariante dengan program SPSS"Semarang Badan Penerbit Universitas UNDIP 